\title{
Determinants of Successful Implementation of Audit Report Recommendations: The Case Office of the Federal Auditor General in Northern Branch
}

\author{
Tesega Tadesse Demeke \\ Department of Office of the Federal Auditor General in Northern Branch, Support and Subsidy Audit Directorate, Office of Federal Auditor \\ General, Bahir Dar, Ethiopia
}

Email address:

tesegatadesse@gmail.com

To cite this article:

Tesega Tadesse Demeke. Determinants of Successful Implementation of Audit Report Recommendations: The Case Office of the Federal Auditor General in Northern Branch. Science, Technology \& Public Policy. Vol. 6, No. 1, 2021, pp. 1-9. doi: 10.11648/j.aas.20210601.11

Received: December 30, 2020; Accepted: January 13, 2021; Published: March 10, 2021

\begin{abstract}
This study was carried out in order to investigate the Determinants of successful implementation of audit report recommendation in Office of federal Auditor General Audited Government Organization Northern branch in Bahir Dar. Data collection was achieved through questionnaires and the study of documentary materials. The primary data were supplied to 5 respondents focusing purposively on all audit team leaders and audit manager. The secondary data were generated from the annual summarized audit reports of 265 previously audited government organizations prepared by Office of federal Auditor General in Northern branch. The test of hypotheses and other analysis of data were done using SPSS, version 20. The tests revealed that among others, conflicts of interest, lack of follow up, employee instability and management resistance are the significant factors affecting successful implementation of audit recommendation in Northern branch. That means they are the principal factors hindering the implementation of audit report recommendation. In addition, it is found that management \& employee negligence and remoteness would likely have negative in-significant effect on the implementation of audit in Northern branch. The study recommends efforts should be made to establish and strengthen follow up for previous audits, create awareness for the legal punishment related to conflict of interest and design proper information exchange system during employee turnover to improve implementation of audit recommendation. Also, regulatory authorities should exercise legal measure for management negligence and resistance for the successful implementation of audit recommendation.
\end{abstract}

Keywords: Audit Recommendation, Implementation, Audited Entities and External Audit

\section{Introduction to the Study}

The implementation of audit report recommendations is the most visible way for the audit process to add value to the entity. To encourage management buy-in and commitment, it is important that recommendations are developed in consultation with the management responsible for the area audited [1]. To assist in achieving timely remedial action, audit reports should also include an action plan and a realistic timeframe, agreed with management, for the implementation of the recommendations.

The management of the audited entity is responsible to communicate the actions taken on recommendations on time as specified and suggested by the auditor [4].
Giving readers an adequate and correct understanding means providing perspective on the extent and significance of reported findings, such as the frequency of occurrence relative to the number of cases or transitions tested and the relationship of the findings to the entity's operations. In most cases, a single example of a deficiency is not sufficient to support a broad conclusion or a related recommendation. All that it supports is that an error, deviation or weakness existed. However, except as necessary to make convincing presentation detailed supporting data need not be included (ibid). As explained above audit has a long history, but researches are rarely conducted in this area. Therefore the purpose of this study is designed to inspect the Determinants of successful implementation of audit report recommendation 
in Office of federal Auditor General Audited Government Organization in Northern branch in Bahir Dar.

Audit is done to ascertain the validity and reliability of the financial statements prepared by government organizations based on specific auditing standards. Head of public bodies have the 'duty to ensure that all of the resources for which they are using only for proper and approved purposes, and that they are used in the most economical, efficient and effective way [3].

So to overcome the above indicated problem the study intends to conduct this study to identify and recommend the mechanism to mitigate the Determinants of successful implementation of audit report recommendation in Office of federal Auditor General Audited Government Organization in Northern branch.

The general objective of this study is to investigate the Determinants of successful implementation of audit report recommendations by audited government entities by Office of federal Auditor General Northern Branch in Bahir Dar.

Based on the general objective stated above this study specifically tries:

1) To examine the effect of conflict of interest by Audited Government Organization's management \& employees on implementation of audit report recommendation.

2) To examine the effect of negligence by Audited Government Organization's management \& employees on implementation of audit report recommendation.

3) To examine the effect of lack of follow up by Office of federal Auditor General on implementation of audit report recommendation.

4) To examine the effect of Audited Government Organization's employee instability on implementation of audit report recommendation.

5) To examine the effect of Audited Government Organization's management resistance on implementation of audit report recommendation.

The study is centered to examine the factors that affect audited entity's management to take corrective action on audit report recommendations supplied by Office of federal Auditor General Northern Branch in Bahir dar in the case of Northern Branch audited government organizations. The organizations audited from 2008 - 2011 E.C (for 4 years) used as a base to detect the degree /extent/ of implementation of audit report recommendation.

\section{Literature Review}

An audit is a systematic process of objectively obtaining and evaluating evidence regarding assertions about economic actions and events to ascertain the degree of correspondence between these assertions and established criteria, and communicating the results to interested users. In the process of the audit, accounting records are analyzed by the auditors using a variety of generally accepted techniques. An audit is an independent, objective and expert examination and evaluation of evidence. Auditors are fair and do not allow prejudice or bias to override their objectivity. The audit is conducted with the aim of expressing an informed and credible opinion in a written report [10].

The objective of an audit of financial statements is to enable an independent auditor to express an opinion as to the fairness of presentation, in all material respects, of an entity's financial position, results of operations, and cash flows in conformity with GAAS [8].

According to General Accounting Office to achieve the desired action, recommendations must have the following characteristics [8]:

Properly directed:

Recommendations should be directed to those who have responsibility and authority to act on them. At times, recommendations are directed to people who have a number of roles. The recommendation should state the role that applies.

Hard-hitting: There should be no doubt that a recommendation has been made. Recommendations should be clearly labeled as such, not hidden, or obscured by text. They should be readily identifiable and stand out in the report.

Specific: Recommendations should state as specifically as possible just what action should be taken. This is a matter of degree. Audit recommendations do not tell how to develop a system, but they should be specific about the system that needs improvement and the objectives that should be achieved by the change.

Recommendations for additional studies should be made only in rare cases and for very good reasons. When such a recommendation is made, it should be worded in a way that demonstrates the need for additional work without calling into question the value of the audit work being reported.

Convincing: Recommendations should be well-supported by facts and should flow logically from these facts. This connection can be made by placing the recommendation close to the finding or by inserting language in the recommendation.

The information presented should be sufficient to convince the readers to recognize the validity of the findings, the reasonableness of the conclusions, and the benefit of implementing the recommendations. Reports designed in this way can help focus the attention of responsible officials on the matters that warrant attention and can help stimulate correction [4].

Significant: A decision on a recommendation is influenced by the significance of the deficiency that it would correct. The finding and the recommendation must clearly demonstrate that acting on the recommendation will improve operations, safeguard assets, or bring the situation in compliance with laws and regulations [6].

Positive in tone and content: Positive, constructive statements are more likely to get action than negative ones.

The tone of reports should encourage decision-makers to act on the auditors' findings and recommendations. Although findings should be presented clearly and forth-rightly, the auditors should keep in mind that one of their objectives is to persuade, and that this can best be done by avoiding language 
that generates defensiveness and opposition. Although criticism of past performance is often necessary, the report should emphasize needed improvements [4].

According to Regularity Audit Mannual an audit finding is a written explanation of errors, weaknesses, deficiencies, adverse conditions, or the need for improvements or changes that are disclosed in an audit [2]. It is a constructively critical commentary on actions or inactions, which, in the auditor's judgment, hinder the accomplishment of desired objectives in an effective and efficient manner. An audit finding usually is accompanied by a recommendation for specific action to correct the cited deficiency. Normally, audit reports concentrate on informing management about things that call for corrective action (findings).

According to Regularity Audit Mannual audit report that delivered to audited organization by Office of Auditor General has four sections [2]. These are: - finding, cause, effect and recommendation.

Audit Finding:

This section describes the circumstances surrounding the finding, present facts supporting the finding, and provides the reader with sufficient qualitative and quantitative evidence.

Cause:

This section document the underlying reason for the questionable behavior or condition.

Effect:

This section documents the actual or potential adverse effects which have resulted or could result from the condition being questioned.

Recommendation:

This section documents the potential benefit the audited entity would receive if the recommended corrective action is implemented. The benefits are often the elimination or reduction of risks noted in the "Effect" section.

Office of the State Auditor [9] reported audit recommendation implementation using Annual Report of Audit Recommendations Not Fully Implemented As of June 30, 2013. The finding shows that:

".....OUR CONCLUSION: when considering the number of recommendations that the OSA has made to state agencies over the last 5 years, state agencies generally agree with our recommendations and usually implement them in a timely manner. However, there are some recommendations that have not been fully implemented and are still outstanding."

After detail review of related literature, the following conceptual framework is developed based on literature review as shown in

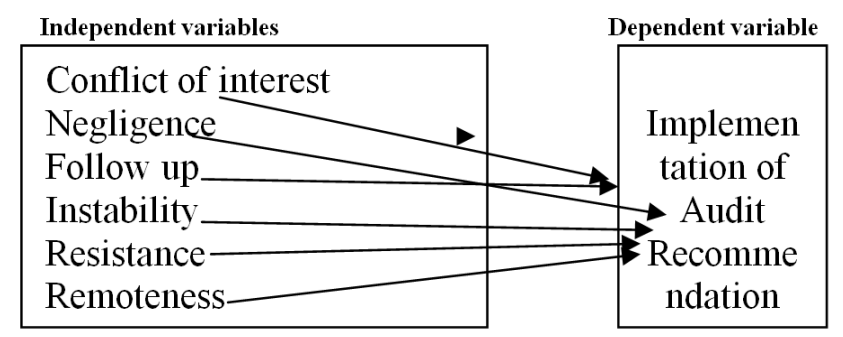

Figure 1. Conceptual frame work.

\section{Research Design and Methodology}

In fact, the research design is the conceptual structure within which research is conducted; it constitutes the blueprint for the collection, measurement and analysis of data. As such the design includes an outline of what the researcher will do from writing the hypothesis and its operational implications to the final analysis of data [7].

There are two basic approaches to research, viz., quantitative approach and the qualitative approach. The quantitative approach involves the generation of data in quantitative form which can be subjected to rigorous quantitative analysis in a formal and rigid fashion. Qualitative approach to research is concerned with subjective assessment of attitudes, opinions and behavior. Research in such a situation is a function of researcher's insights and impressions [7].

The study conducted on secondary data in northern part of Office of federal Auditor General audited organization from 2008-2011 E.C. The northern part has 265 organizations which are potentially audited by Office of federal Auditor General.

The study employed both primary and secondary data. The primary data obtained through questioner from Office of federal Auditor General northern branch audit manager and team leaders and the secondary data obtained through observation from audit recommendations given by Office of federal Auditor General to the audited entity and annual summarized issued. Dependent variables are resulted due to independent variables. Implementation of audit recommendation is dependent variable that influenced by Conflict of Interest, Negligence, Lack of follow up, Instability, Resistance and Remoteness. For this research, the researcher used both primary and secondary data. Primary data has obtained from audit manager and team leaders of Office of federal Auditor General using self-administered questionnaires, being as the best data collecting tool. This is because questionnaire is the least expensive, time saving and encourages the respondents to fill their feeling, which consisting of close ended questions. These close ended questionnaires have been designed according to the objectives and study variables, and responses to the questions have been fastened on a five (5) point Likert scales ranging from strongly disagree (1) to strongly agree (5).

The primary data collected by way of questionnaires and the documentary data obtained from secondary sources formed the basis of analyzing the research findings. After collecting the data, it has been edited, coded and checked to have the required quality, accuracy and completeness. Then data was analyzed using an SPSS (statistical package for social science) tool which can provide descriptive outputs. Correlation analysis tools have been carried out to establish the strength of the relationship between variables. The multiple regression analysis also used to determine how the predictor variables could explain the dependent variable. This is because there is more than one variable affecting the dependent variable. 
In the Regression Analysis, the multiple regression models have been used to determine the effect of independent variables (conflict of interest by Audited Government Organizations' management \& employees, Audited Government Organizations' management \& employees negligence, lack of follow-up by Office of federal Auditor General, instability of Audited Government Organizations' employees, remoteness of Audited Government Organizations from Office of federal Auditor General and Audited Government Organizations' management resistance) on the dependent variable (implementation of audit recommendation). OLS Model IARRi $=\alpha+\beta 1 \mathrm{CI} i+\beta 2 \mathrm{Ni}+\beta 3 \mathrm{LFi}+\beta 4 \mathrm{IEi}$ $+\beta 5$ RAARi $+\beta 6$ RAOOFAG i + ei

Assumption

1. The random variable (ei) is independent of the explanatory variables (since independent variables are exogenous). This means there is no correlation between the random variable and the explanatory variable.

2. No auto correlation between the errors. This means the value which the random term assumed in one period does not depend on the value which it assumed in any other period.

3. No 'perfect multi co-linearity between independent variables. That is, no explanatory variable can be written as a linear function of other explanatory variables. The details of test results are presented in results and discussion part.

\section{Data Analysis and Presentation}

In this study seven variables were of interest, the variables include conflict of interest on Audited Government Organizations' management \& employees, Negligence on Audited Government Organizations' management \& employees, lack of follow up by Office of federal Auditor General, instability of Audited Government Organizations' employees, resistance of Audited Government Organizations' management to accept audit recommendation, remoteness of Audited Government Organizations from Office of federal Auditor General and implementing audit report recommendation. Descriptive analysis was conducted on the whole data set for variables in order to understand its nature and types of distribution (mean, and standard deviation).

The respondents were asked to raise their views on conflict of interest by audited entity management and employees to implement audit report recommendation in the branch. From the research data, $40 \%$ agree, $48.9 \%$ and $11.1 \%$ indicated that disagree and neutral respectively.

some respondents disagreed (Mean $\approx 3$, and the Std deviation is insignificant) that they are considering management members and employees of the audited organization are not highly interested to audit and the organization management is not highly cooperative for auditing to investigate complex mischief. While some respondents were highly agreeable (Mean $\approx 4$, and the Std deviation is insignificant) with management members of the organization are the cause roots of fraud $\&$ mischief, favor for employees who have close relation with them during implementing recommendation and audited organizations' employees show their negative interest to audit through delay access of documents, not give clear $\&$ timely explanation on audit queries and resist to accept audit comments.

The mean of conflict of interest was $2.87 \approx 3$, which are in the average of a high agreeing on the items designed to measure the variable. It ensures that conflict of interest highly agreeable in the part of the respondents. The standard deviation of conflict of interest is 0.927 which is far from the mean.

According to the respondents' views on negligence $76.2 \%$ of the respondents agreed, $15.3 \%$ disagreed and $8.6 \%$ indicated that neutral. It displays that the extent of negligence and its effect on implementing audit recommendation, which the respondents feeling is high as the average mean of the respondent is 2.18 . While some respondents were highly agreed (Mean $\approx 4$, and the Std deviation is insignificant) with audited organizations repeat basic mistakes and irregularities that had been recommended in the previous audit. In addition to this revealed as some respondents disagreed (Mean $\approx 2$, and the Std deviation is insignificant) that the organization employees are actively participating when the audit is conducting; audited organizations are performing corrective actions critically by focusing on technical failure and audited organizations are doing their correction assignment and inform to Office of federal Auditor General at the specified date.

The respondents' views on lack of follow up shown below: the effect of lack of follow up on implementing audit recommendation based on the respondents response is $34.6 \%$ disagreed, $57.3 \%$ agreed and $8 \%$ neutral. It displays the extent of follow up and its effect on implementing audit recommendation which the respondents feeling is disagree as the mean of the respondent is 2, that there is strong, continuous and practical follow up system for previous audit finding implementation by Office of federal Auditor General. In addition to this revealed that most respondents agreed (Mean $\approx 4$, and the Std deviation is insignificant) that mostly audited organizations respond false report for audit recommendation as if they correct properly. More respondents were highly agreed (Mean $\approx 4$ and the Std deviation is insignificant) on strong and continuous follow up makes management responsible for correcting audit recommendation and absence of follow up on implementing audit recommendation results wastage of public resources. Therefore, when there is no strong and continuous follow up by Office of federal Auditor General Audit recommendations not implemented properly and leads to wastage of public resources.

The audit manager views on the instability of employees, as, indicated that $66.6 \%$ agreed, $13.3 \%$ disagree and the rest $20 \%$ neutral. At the same time it displays the extent of effect of employees' instability on implementing audit recommendation, which the respondents feel, is highly agree as the average mean of the respondent is nearly 3. Meaning, audit manager agree on the negative influence of audited 
organizations' employee turnover which leads to not implementing audit recommendation. majority of respondents agreed (Mean $\approx 4$, and the Std deviation is insignificant) for two questions that Audited Government Organizations' employee turnover highly affects implementing audit report recommendation and from your experience the turnover of employees in audited organization is high. And majority of respondents disagreed (Mean $\approx 2$, and the Std deviation is insignificant) on two questions that there is information exchange between former and new employees about audit recommendation; new employees of audited organizations examine audit files to care for mistakes that will happen in the future. Therefore, when there is employee turnover in audited entities, audit recommendations not implemented properly.

The extent of management resistance and its effect on implementing audit recommendation, which the respondents reaction is high as the average mean of the respondent is $2.73 \approx 3$. As most respondents disagreed (Mean $\approx 2.13$, and the Std deviation is insignificant) that all audited entity's management eager to participate and acquire knowledge about how to implement audit recommendation. In addition most respondents agreed (Mean 3.33 3 , and the Std deviation is insignificant) that management of audited organizations fear punishment that will come in the future based on audit recommendation. Therefore, if the punishment will be exercise based on audit recommendation on AEs' management, the audit recommendation not accepted and implemented properly by management.

The respondents' views on remoteness $44.4 \%$ of them disagree, $33.4 \%$ agree and the rest $22.2 \%$ neutral. It displays the extent of remoteness and its effect on implementing audit recommendation, based on the respondents experience implementation of audit recommendation is adversely affected by remoteness with the average mean of the respondents 3. In addition to this revealed that most respondents agreed (Mean 3.47 $\approx 4$, and the Std deviation is insignificant) that most of audited organizations in the region are too far from Office of Auditor General. Majority of respondents also disagreed (Mean $\approx 2$ and the Std deviation is insignificant) with audited organizations are implementing audit recommendation, even if they are far from Office of federal Auditor General. Therefore, remoteness can affect implementing audit recommendation adversely.

Implementing audit recommendation, which the respondents believe is strong as the average mean of the respondent is 2.428 . The results indicated that $25.3 \%$ of the respondents agreed, $62.7 \%$ of them disagreed and the rest $12 \%$ neutral. As most respondents disagreed (Mean $\approx 2$, and the Std deviation is insignificant) that audit recommendations especially which have relation to management members of the audited entity have been corrected properly. Majority of respondents agreed (Mean $\approx$ 4 , and the Std deviation is insignificant) that there is a legal ground to take measure on organizations' management \& employees when they would not be positive to audit. In addition to this majority of respondents disagreed (Mean $\approx$ 2 , and the Std deviation is insignificant) that Office of Auditor General follow implementation of all audit report recommendation. Therefore, audit recommendations not successfully implemented for employees who has close relation to Audited Government Organizations' management; there is legal ground to take measure for not cooperative for audit and Office of federal Auditor General not make follow up to confirm the extent of audit recommendation implementation.

Test of correlation is used to test the degree of relationships between variables under study. The objective of the test is to see whether there are many multicolinearity problems among variables. The problem exists if independent variables are highly correlated among each other with correlation values exceeding 0.90 [12]. High correlation among independent variables reduces the explanatory power of the variables on the dependent variable [11]. The Pearson's correlation coefficient (r) was run to determine the relationship between the variables. Results of the test are presented in Table 1. which shows the correlation values among independent variables. The correlation result is shown below:-

Table 1. Pearson's Correlation Matrixes

\begin{tabular}{|c|c|c|c|c|c|c|c|}
\hline Variables & 1 & 2 & 3 & 4 & 5 & 6 & 7 \\
\hline Conflict of interest (1) & 1 & & & & & & \\
\hline Negligence (2) & .040 & 1 & & & & & \\
\hline Instability of employees (4) & -.507 & .260 & -.148 & 1 & & & \\
\hline Resistance of management (5) & -.304 & .356 & -.322 & .199 & 1 & & \\
\hline Remoteness of audited organization from OFFICE OF FEDERAL AUDITOR GENERAL (6) & -.062 & .294 & -.081 & -.058 & .173 & 1 & \\
\hline Implementing audit recommendation (7) & -.224 & $-.559^{*}$ & $-.555^{*}$ & -.313 & -.270 & -.195 & 1 \\
\hline
\end{tabular}

*. Correlation is significant at the 0.05 level (2-tailed).

The Relationship between Conflict of interest and Implementation of Audit Recommendation

The results in the table 1 . shown above is that there is a negative relationship between conflict of interest and implementing audit recommendation $(r=-0.224)$. Therefore, when conflict of interest increases, implementing audit recommendation decreases and vice versa. This means audit recommendations are properly implemented if conflict of interest on audited entity management and employees decrease. For example, if audited entities management and 
employees are interested for audit and free from conflict of interest, they encourage auditors to investigate complex mischief and audit findings properly corrected by them.

The Relationship between Negligence and Implementing audit Recommendation

The results in the table 1 . shown above is that there is a significant negative relationship between negligence and implementing audit recommendation $\left(\mathrm{r}=-0.559^{*}, \mathrm{p}=0.05\right)$. Therefore when Audited Government Organizations' management and employees are negligent to take corrective action on audit comments, audit recommendations are not implemented successfully and vice versa. If audited entities management \& employees are actively participating by supplying documents for examination, acquire knowledge how to correct previous findings and understand the benefit of audit $\&$ the legal measure related to this area, audit recommendations implemented properly. But if audited entities management \& employees are negligent to audit, audit recommendations are not implemented and basic mistakes are occurring always.

The Relationship between Lack of follow up and Implementing Audit Recommendation

As shown above in table 1 . there is a significant negative relationship between lack of follow up and implementing audit recommendation $\left(\mathrm{r}=-0.555^{*}, \mathrm{p}=0.05\right)$. When follow up by Office of federal Auditor General not performed, successful implementation never gets on audit recommendation delivered by Office of federal Auditor General to audited entities and vice versa. This means follow up makes pressure on audited organization employees and management to take corrective action properly at the specified time. Generally practical strong and continuous follow up by Office of federal Auditor General is not sufficient and it leads to wastage of public resource.

The Relationship between Instability of Employees and Implementing Audit Recommendation

The results in the table 1 shown above is that there is a negative relationship between instability of employees and implementing audit recommendation $(\mathrm{r}=-.313)$. Therefore, when the audited organization employees' turnover increases, the implementation of audit recommendation is not sufficient \& effective and vice versa. This means instability of employees affect implementation of audit recommendation negatively.

The Relationship between Resistance of Management and Implementing Audit Recommendation

The results in the table 1 shown above is that there is a negative relationship between the resistance of management and implementation of audit recommendation $(r=-0.270)$. This implies if there is resistance to accept audit recommendation by management of audited entity, there will be a decrease in implementing audit recommendation and vice versa. For instance, if the management of audited entities accepts audit recommendation after great resistance, corrections would not be successful, and they create another reason to care for their grace. Therefore management resistance and implementing audit recommendation are negatively correlated.

The Relationship between Remoteness and Implementing Audit Recommendation

The results in table 1 above show that there is a negative relationship between remoteness and implementing audit recommendation $(\mathrm{r}=-0.195)$. This means that the remoteness of audited organization from Office of federal Auditor General can affect negatively implementation of audit recommendation. For instance, if Audited Government Organizations located too far from Office of federal Auditor General, audited entities' management \& employees would not be committed to carry-out their assignment. Therefore they didn't take proper corrective action based on recommendation.

Regression Assumption Checks

Before testing the hypothesis, the regression assumption of multi colinearity is checked. One method to detect high multi colinearity is variance-inflating factor (VIF).

Table 2. Multi colinearity between Independent Variables.

\begin{tabular}{|c|c|c|}
\hline \multirow{2}{*}{ Variables } & \multicolumn{2}{|c|}{ Co-linearity statistics } \\
\hline & Tolerance & VIF \\
\hline Conflict of interest by Audited Government Organizations' management \& employees & .616 & 1.624 \\
\hline Negligence of Audited Government Organizations' management \& employees & .581 & 1.722 \\
\hline Lack of follow up by Office of federal Auditor General & .746 & 1.341 \\
\hline Instability of Audited Government Organizations' employees & .608 & 1.645 \\
\hline Resistance of Audited Government Organizations' management to accept audit recommendation & .648 & 1.542 \\
\hline Remoteness of Audited Government Organizations from Office of federal Auditor General FEDERAL AUDITOR GENERAL & .841 & 1.189 \\
\hline
\end{tabular}

It measures how the variance of an estimator is inflated by the presence of multi colinearity. With zero correlation between the independent variables, VIF equals 1. [5] Suggests that a value of VIF greater than 10 indicates a problem.

According to this study the VIF is found to be less than 1.722. Therefore there is no multicolinearity between independent variables.

Regression Analysis
A regression was run to determine the predictive power of the independent variables (conflict of interest, negligence, lack of follow up, instability of employees, resistance of management, and remoteness of audited organization from Office of federal Auditor General in explaining implementing audit report recommendation on Audited Government Organizations in north region. 
Table 3. Regression Model of Independent and Dependent Variable Coefficients ${ }^{a}$.

\begin{tabular}{llllll}
\hline \multirow{2}{*}{ Model } & \multicolumn{2}{l}{ Un standardized Coefficients } & \multicolumn{2}{l}{ Standardized Coefficients } & \multirow{2}{*}{ Sig. } \\
\cline { 2 - 4 } & B & Std. Error & Beta & & \\
\hline (Constant) & 12.707 & 1.747 & & 7.273 & $0.000^{*}$ \\
Conflict of interest & -1.446 & .435 & -.529 & -3.325 & $0.010^{*}$ \\
Negligence & -.012 & .352 & -.005 & -.033 & 0.974 \\
Lack of Follow up & -.573 & .119 & -.698 & -4.227 & $0.001^{* *}$ \\
Instability of employees & -.805 & .216 & -.598 & -3.735 & $0.006^{* *}$ \\
Resistance of Management & -.437 & .137 & -.495 & -3.193 & $0.013 *$ \\
Remoteness from office of federal auditor general & -.251 & .148 & -.231 & -1.700 & 0.128 \\
\hline
\end{tabular}

$\mathrm{R}=.936, \mathrm{R}$ Square $=.875$, Adjusted $\mathrm{R}$ Square $=.782$, Std. Error of the Estimate $=.25684$

$\mathrm{R}$ square Change $=.875, \mathrm{~F}$ Change $=9.352(\mathrm{P}$-value $=0.000)$, Sig. 0.003

Dependent Variable: Implementation

Note:- * Significant at the 0.05 level

** Significant at the 0.01 level

From the above table, it can be formulated as: IARRi $=\alpha+$ $\beta 1 \mathrm{CIi}+\beta 2 \mathrm{Ni}+\beta 3 \mathrm{LFi}+\beta 4 \mathrm{IEi}+\beta 5 \mathrm{RAARi}+\beta 6 \mathrm{RAOOFAG} \mathrm{i}$ + ei IARRi $=12.707-1.446 \mathrm{CIi}-0.012 \mathrm{Ni}-0.573 \mathrm{LFi}-$ 0.805IEi - 0.437RAARi - 0.251RAOOFAG i + ei

The predictive power of the model is shown by $\mathrm{R}$ Square. $\mathrm{R}$-Square is a measure of how well the model is able to predict the changes in the actual data. R-Square ranges between 0 and 1 , with values over 0.5 indicating a good fit between the predictions and actual data [9].

The regression results on the above table 3 verified that independent variables (conflict of interest by Audited Government Organizations, negligence of Audited Government Organizations' management \& employees, lack of follow up by Office of federal Auditor General, instability of Audited Government Organizations' employees, resistance of Audited Government Organizations' management and remoteness of audited entities from Office of federal Auditor General) explain $87.5 \%$ of the variation in implementing audit recommendation, indicating a good fit since it is above $50 \%$. This implies that other factors not in the current study accounted for the remaining $12.5 \%$ of variance in implementing audit recommendation. Except negligence of Audited Government Organizations' management \& employees and remoteness of audited entities from Office of federal Auditor General, all the predictors were observed to be more significant predictors of implementation of audit recommendation at sig $<0.05$ and sig $<0.01$. The regression model by itself is statistically significant at the $1 \%$ \& $5 \%$ level $(\mathrm{F}$-value $=9.352, \mathrm{p}<0.003)$.

\section{Conclusions}

The multiple regression results revealed that conflict of interest by Audited Government Organizations, negligence of Audited Government Organizations' management \& employees, lack of follow up by Office of federal Auditor General, instability of Audited Government Organizations' employees, resistance of Audited Government Organizations' management to accept audit recommendation and remoteness of Audited Government Organizations from Office of federal Auditor General explain high variation on implementing audit recommendation, indicating a good fit since it is above the minimum standard level. This implies that other factors that are not included in the current study accounted for the remaining small variance in implementing audit recommendation. The regression model by itself is statistically significant at the 5\% level.

The multiple regression analysis confirmed that conflict of interest by audited organizations' management and employees have negative significant effect on audit recommendation implementation. In addition to this, the descriptive statistics result show that management members and employees of the audited organization are not highly interested to audit; the organization's management is not highly cooperative for auditing to investigate complex mischief; management members of the organization are the cause roots of fraud \& mischief; Audited Government Organizations' management favor for employees who have close relation with them during implementing recommendation and Audited Government Organizations' employees show their negative interest to audit through delay access of documents, not give clear $\&$ timely explanation on audit queries and resist to accept audit comments. It can be concluded that, it is not easy to get successful implementation on audit recommendation based on audit findings. Hence, the personal interest of Audited Government Organizations' management and employees can be cited as the major factor that has contributed to the underlying problem and so that they are responsible for poor performance of audit recommendation implementation. Thus, regarding the influence of conflict of interest by Audited Government Organizations' management and employees, further study need to be done to empirically test their effect on successful implementation of audit recommendation.

Even if the multiple regression analysis communicated that negligence of Audited Government Organizations' management $\&$ employees has a negative but not significant effect on audit recommendation implementation, the descriptive statistics result show that audited organizations repeat basic mistakes and irregularities that had been recommended in the previous audit; the audited organizations' employees are not actively participating when the audit is conducting; audited organizations 
are not performing corrective actions critically by focusing on technical failure and audited organizations are not doing their correction assignment \& inform to Office of federal Auditor General at the specified date. Generally if Audited Government Organizations' management \& employees are negligent, the successful implementation of audit recommendations might be declined.

The multiple regression analysis discovered that lack of follow up by Office of federal Auditor General has negative significant effect on audit recommendation implementation, and holding other independent variables constant, it has more influence on audit recommendation implementation. As far as lack of follow up increases, successful implementation of audit recommendations would be decreases. Because the strong and continuous follow up for previous audits lead to initiate Audited Government Organizations for correcting audit comments. The descriptive statistics result also show that there is no strong, continuous and practical follow up system for previous audit finding implementation by Office of federal Auditor General. In addition to this, most respondents agreed that mostly audited organizations respond false report for audit recommendation as if they correct properly; strong and continuous follow up makes management responsible for correcting audit recommendation and absence of follow up on implementing audit recommendation results wastage of public resources. Therefore, lack of follow up is highly negative determinant factor for successful implementation of audit comments.

The multiple regression analysis disclosed that instability of Audited Government Organizations' employees has negative significant effect on implementation of audit recommendation, and holding other independent variables constant, it has more influence on audit recommendation implementation. The descriptive statistics result also show that the majority of audit managers' views on instability of Audited Government Organizations' employees agreed on the high turnover of employees in audited organizations and highly affects implementing audit report recommendation. And majority of respondents disagreed on two questions that there is information exchange between former and new employees about audit recommendation and new employees of audited organizations examine audit files to care for mistakes that will happen in the future. Therefore, when employees' turnover on Audited Government Organizations is high, there would be poor performance on correcting audit recommendation.

The multiple regression analysis introduced that Audited Government Organizations' management resistance to accept audit recommendation has negative significant effect on implementing audit recommendation, and holding other independent variables constant, it has more influence on implementing audit recommendation. As far as Audited Government Organizations' management resistance to accept audit recommendation increases, implementation of audit recommendation would be decreases. Because the existence of high management resistance lead to hide audit recommendations to safe from the legal measure that will be taken by higher government body. The descriptive statistics result also show that majority of respondents disagreed that audited entity's management eager to participate and acquire knowledge about how to implement audit recommendation; most respondents agreed that management of Audited Government Organizations fear punishment that will come based on audit recommendation. Therefore, audited organizations' management resistance highly decreases successful implementation of audit recommendation.

The multiple regression analysis demonstrated that the remoteness of audited entities from Office of federal Auditor General has no significant effect on implementation of audit recommendation, and holding other independent variables constant, it has no influence on audit recommendation implementation, despite the fact that their relationship is negative. This means that remoteness does not influence implementing audit recommendation as such or we can say that the effect is too little. On the other hand, the descriptive statistics result show that most respondents agreed that most of audited organizations in the region are too far from Office of federal Auditor General and majority of respondents also disagreed with audited organizations are implementing audit recommendation, even if they are far from Office Of Federal Auditor General. Therefore, remoteness can affect implementing audit recommendation adversely.

Generally, conflicts of interest by Audited Government Organizations' management \& employees, lack of follow up by Office of federal Auditor General, instability of Audited Government Organizations' employees and Audited Government Organizations' management resistance have negative significant influence on implementing audit recommendation. And Audited Government Organizations' management \& employees' negligence and remoteness of Audited Government Organizations from Office of federal Auditor General have negative but not significant effect on implementing audit recommendation.

\section{Recommendations}

The finding of the study confirmed that conflict of interest by audited entities' management $\&$ employees has negative significant effect on implementing audit recommendation. Audited entities' management \& employees have the responsibility to administer public resources, serve the public and open their door for check and balance. Additionally, they accomplish their responsibility with integrity manner, show demand for audit and should implement all audit recommendations. So to address this fact the regional government should create awareness podium for audited entities' management \& employees about their responsibility, the immoral act of rent seeking, and the legal measure that will be taken on dishonest management $\&$ employees.

It is observed that instability of audited entities' employees has negative significant effect on implementing audit recommendation. Even if employees have the right to move from one organization to another, they have obligation to transfer the real information for new comers or the retained employees. So government officials should design and put into 
practice the system which is the former employees transfer audit assignments to the new employees and new employees examine audit assignments cautiously to implement previous recommendation and to be careful for future mistakes.

The finding of the study confirmed that the resistance of audited entities' management to accept audit recommendation has negative significant effect on implementing audit recommendation. Management of audited entities has the responsibility to show their demand for audit, accept and implement audit recommendation. But they are not in a position to do this. So to alleviate this problem the regional government should perform awareness creation about the benefit of audit recommendation \& the legal measure that will be taken on such government executives that give attention for their grace rather than audit benefit.

The result of the study concluded that negligence of audited entities' management \& employees and remoteness of audited entities from Office of federal Auditor General have negative and insignificant effect on implementing audit recommendation. Hence, there is a need to improve on implementing audit recommendation. This could be done through intensive education about the benefit of audit and the legal action relating to non-implementing audit recommendation by regional government.

\section{Acknowledgements}

Above all, my deepest thank goes to the source of everything and the kindhearted God, without him I wouldn't have come up this result.

Besides, I want to address my sincere thanks for the respected principal advisor Zebenay Workineh for his kind, unreserved help and persistent guidance in the preparation of this journal.

\section{References}

[1] Australian National Audit Office (ANAO) continue to deliver high quality audit reports to ensure it delivers against its mandate under the Auditor-General Act 1997 (the Act). On 21 February 2018, the Prime Minister and Cabinet Legislation Amendment (2017).
[2] AFROSAI-E. (2012). Regularity Audit Mannual.

[3] Board, C. P. (2011). Enhancing Audit Quality: Conclusions and Recommendations.: Chartered Professional Accountants of Canada.

[4] Board, C. P. (2013). Enhancing Audit Quality: Conclusions and Recommendations. Toronto: Chartered Professional Accountants of Canada.

[5] EAP (2003). FINANCIAL AUDIT MANUAL: Audit Evaluation/Completion, Reporting and Follow-up., (p. 75).

[6] Gujarati, D. N. (2004). Basic Economics - fourth edition, the McGraw - Hill Companies.

[7] GAO. (1991). How to Get Action on Audit Recommendation.

[8] Kothari, C. (2004). Research Methodology: Methods and Techniques second revised edition. New Delhi - 110002: New Age International (P) Ltd.

[9] Nick A. Dauber et al. (2008). The Complete Guied to AUDITING STANDARDS AND OTHER PROFESSIONAL STANDARDS FOR ACCOUNTANTS. New Jersey: John Wiley \& Sons, Inc.

[10] OFFICE OF THE STATE AUDITOR (2013). Annual Report of Audit Recommendations Not Fully Implemented. COLORADO.

[11] OAG. (2010, 7 1). Annual Plan. Annual Plan 2010-2013.

[12] Perry M. Henderson et al. (2012). TOP AUDITING ISSUES FOR 2013 CPE COURSE. Chicago: Wolters Kluwer business.

[13] Rick Hyes et al. (2005). PRINCIPLES OF AUDITING: An Introduction to International Standards on Auditing second edition.

[14] (Sharma, 1996). Australian public companies have been required to report a statement of cash flows since 30 June 1992. Since then, little has been written on the usefulness of the cash flow statement. This paper sugge. Cited by: 3 Publish Year: 199

[15] Tabachnick and Fidell 2000. Tabachnick, B. G., \& Fidell, L. S. (2013). Using Multivariate Statistics (6th ed.). Boston, MA: Pearson. has been cited by the following article: TITLE: Development and Piloting the MMMM Ecological Interactive Open Systems. 